\title{
Can volumetric measurement be used in the selection of treatment for inguinoscrotal hernias?
}

\author{
Metin Ertem¹, Hakan Gök², Volkan Özben ${ }^{3}$, Engin Hatipoğlu' ${ }^{1}$, Erdem Yıldız
}

\section{ABSTRACT}

Cite this paper as: Ertem M, Gök H, Özben V, Hatipoğlu E, Yıldız E. Can volumetric measurement be used in the selection of treatment for inguinoscrotal hernias? Turk J Surg 2018; 34: 13-16.

'Department of General Surgery, İstanbul University Cerrahpaşa School of Medicine, İstanbul, Turkey

${ }^{2}$ Department of General Surgery, Acıbadem Kozyatağı Hospital, İstanbul, Turkey

3Department of General Surgery, Acıbadem Atakent Hospital, İstanbul, Turkey

${ }^{4}$ Department of Radiology, Acıbadem Kozyatağı Hospital, İstanbul, Turkey

This study was presented at the $36^{\text {th }}$ International Congress of the European Hernia Society,

28-31 May 2014, Edinburgh, UK.

Address for Correspondence Metin Ertem

e-mail:dr.metinertem@gmail.com

Received: 20.09.2016

Accepted: 26.03 .2017

Available Online Date: 03.01.2018

(C) Copyright 2018

by Turkish Surgical Association

Available online at

www.turkjsurg.com
Objective: Inguinoscrotal hernias are often qualified subjectively as big, giant, scrotal, etc. In order to classify this type of hernia, objective criteria are needed. For this purpose, we aimed to introduce a scrotal volume measurement-based classification system and propose a corresponding surgical plan (open or laparoscopic surgery, anterior or posterior repair) based on volumetric data.

Material and Methods: Between October 2012 and October 2013, 30 consecutive male patients with a mean age of 59.5 years (range: 36 to 82 years) presenting with unilateral ISH were included in this retrospective study. Physical measurements in the upright position and computerized tomography measurements using the Valsalva maneuver were obtained from all patients.

Results: Of the 30 patients, 26 patients had scrotal volumes less than $1000 \mathrm{~mL}$, two patients had SVs between 1001 and $2000 \mathrm{~mL}$, one patient had an SV between 2001 and $3000 \mathrm{~mL}$, and one patient had an SV greater than 3000 $\mathrm{mL}$. Laparoscopic total extraperitoneal repair was performed in patients with scrotal volumes inferior to $1000 \mathrm{~mL}$. In three patients with scrotal volumes between 1000 and $3000 \mathrm{~mL}$, an open posterior approach was used. In one patient with a scrotal volume superior to $3000 \mathrm{~mL}$, no surgical intervention was performed due to the patient's cardiac comorbidity.

Conclusion: By establishing a common language among surgeons, we believe that the volumetric measurementbased scrotal hernia classification system proposed in this study will lead to further studies on the subject.

Keywords: Classification system, inguinoscrotal hernia, scrotal volume

\section{INTRODUCTION}

There is no consensus among surgeons on the classification of inguinal hernias. A survey by Zollinger showed that although the Nyhus, Gilbert, and Schumpelick systems are commonly used, most specialists still use the traditional classification for groin hernias $(1,2)$. Given the large number of operative techniques and approaches for the repair of groin hernias, it appears that no one classification system can satisfy everyone (2). In addition to these, no other classification system, including the European Hernia Society (EHS) classification, has addressed the different types of ISHs (3).

Because the borders of the scrotum have not been described anatomically, it has not been possible to correctly define scrotal hernias. Instead, in the current surgical literature, scrotal hernias are subjectively named scrotal, big scrotal, giant scrotal, etc. However, to develop a common terminology, objective descriptions are needed to identify these different types of hernias. Evaluation of these type of hernias by their volumes could be an objective alternative. For this purpose, scrotal size was measured physically and by computerized tomography (CT) and compared in patients with ISHs. Physical measurements were made to obtain more practical, applicable data.

In this report, we aimed to introduce an objective classification system for ISH and to propose surgical management according to scrotal volumetric measurements.

\section{MATERIAL AND METHODS}

Between October 2012 and October 2013, volumetric measurements of the hernia sac were performed in 30 consecutive patients who were diagnosed with ISHs. After obtaining their informed consent and with the approval of the ethical committee, abdominoscrotal CT scans were performed on all patients. Anatomically, any hernia passing beyond the inguinal ligament and extending into the scrotum was termed an ISH. The values determined by externally measuring the volumes of the hernia sacs were compared with CT measurements.

To obtain measurement correlation, three-dimensional measurements were independently taken by two surgeons and two radiologists. Measurements were taken with a caliper gage while the patient was in the 
Ertem et al.

Volumetric measurement in the treatment selection of inguinoscrotal hernias

standing position, as seen in the illustration (Figure 1). For hernia volume and $\mathrm{CT}$ volume, the largest dimensions were taken for the measurements (Figure 2). The largest height from the inguinal ligament to the lowest identifiable point of the hernia sac in the scrotum was measured. Volumetric measurements were performed while the patient was standing. Measurements of the length, depth, and width of the hernia sac were obtained with a caliper gage. A mathematical formula was used to perform an approximate calculation of the volume of the scrotal hernia sac (4).

\section{Scrotal volume $(S V)=\sim$ length $x$ depth $x$ width $x 0.52$}

When the scrotal volume (SV) was greater than $2000 \mathrm{~mL}$, the ratio of the scrotal and intra abdominal volumes was also analyzed. For this purpose, a second mathematical formula was utilized (4), as given below:

Volume relationship $(V R)=$ scrotal volume/abdominal cavity volume

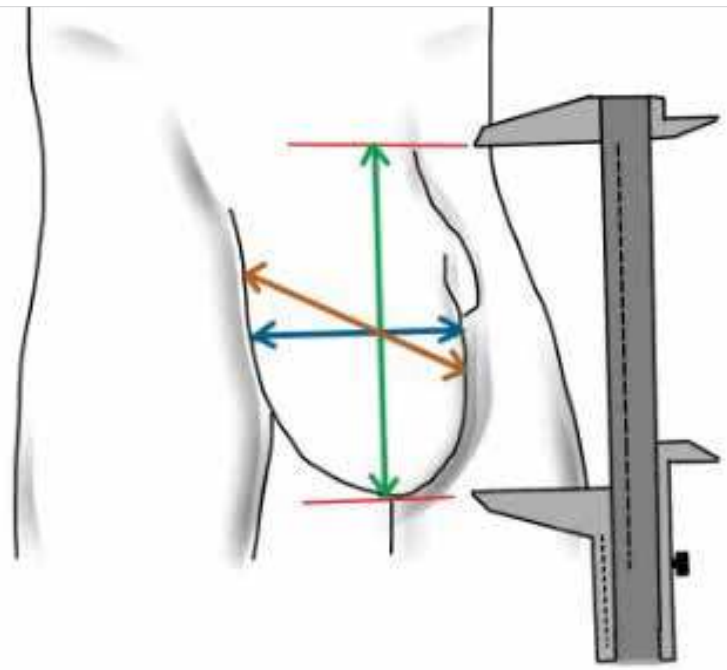

Figure 1. Measurement of external dimensions by caliper gage

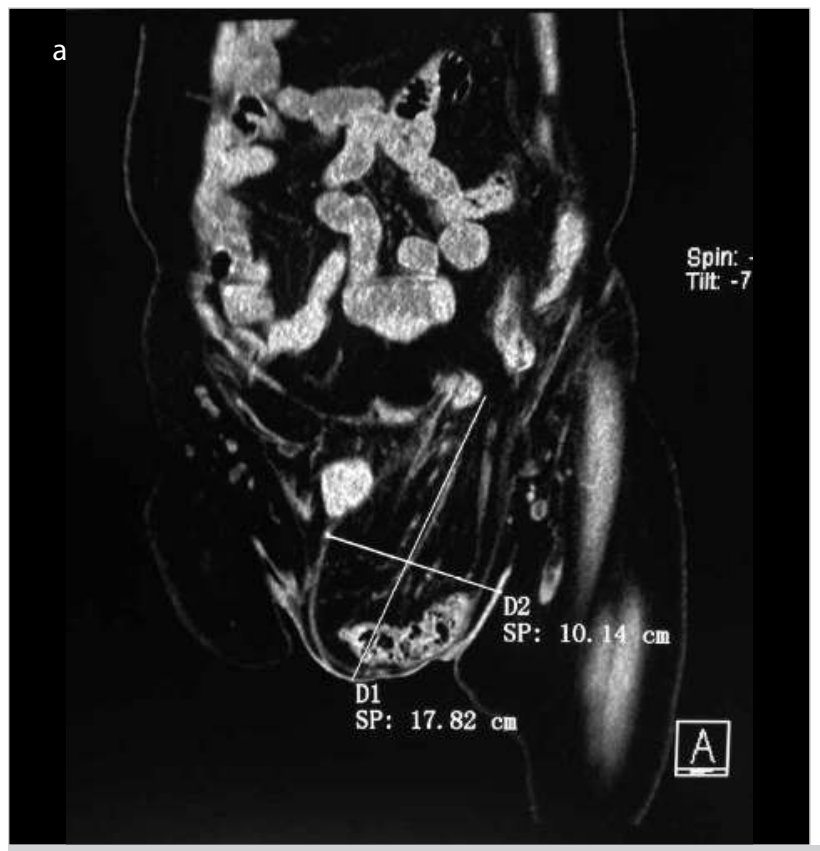

\section{RESULTS}

All the patients were male, with a mean age of 59.5 years (range: 45 to 82 years). All the hernias were unilateral. Of the 30 patients, 26 patients had SVs less than $1000 \mathrm{~mL}$ (CT volume range 94.31 to $849.83 \mathrm{~mL}$ ), 2 patients had SVs between 1001 and $2000 \mathrm{~mL}$ (1098.2 to $1115.40 \mathrm{~mL}$ ), one patient had an SV between 2001 and $3000 \mathrm{~mL}(2357 \mathrm{~mL})$, and one patient had an SV greater than $3000 \mathrm{~mL}(8880 \mathrm{~mL})$. In the two patients with SVs greater than $2000 \mathrm{~mL}$, the scrotal-abdominal volume relationship in the CT scan showed that the VR value was less than $25 \%$ in one patient and greater than $25 \%$ in the other patient.

The intraclass correlation coefficient value (Fisher, 1954, Edinbrugh, United Kingdom), of the standing volume measurements by the two surgeons is 0.992 ( 0.983 to 0.995 , acceptance level $>0.700$ ). The intraclass correlation coefficient value of the CT volume measurements by the two radiologists is 0.995 (0.988 to 0.997 , acceptance level $>0.700$ ) (Table 1$)$. The intraclass correlation coefficient value of the $C T$ volumes and standing volumes is 0.993 (0.986 to 0.997 , acceptance level $>0.700$ ) (Table 2).

There was no statistically significant difference between the CT-scan-based and physically measured volumes $(p=0.121)$ (Table 3).

Table 1. Inter-observer measurement reliability

\begin{tabular}{lccc|} 
& & \multicolumn{2}{c}{$95 \%$ confidence interval } \\
\cline { 3 - 4 } & $\begin{array}{l}\text { Intraclass } \\
\text { correlation } \\
\text { coefficient }\end{array}$ & $\begin{array}{l}\text { Lower } \\
\text { bound }\end{array}$ & $\begin{array}{c}\text { Upper } \\
\text { bound }\end{array}$ \\
\hline Standing volume & 0.992 & 0.983 & 0.995 \\
\hline CT volume & 0.995 & 0.998 & 0.997 \\
\hline CT: computerized tomography & & \\
\hline
\end{tabular}

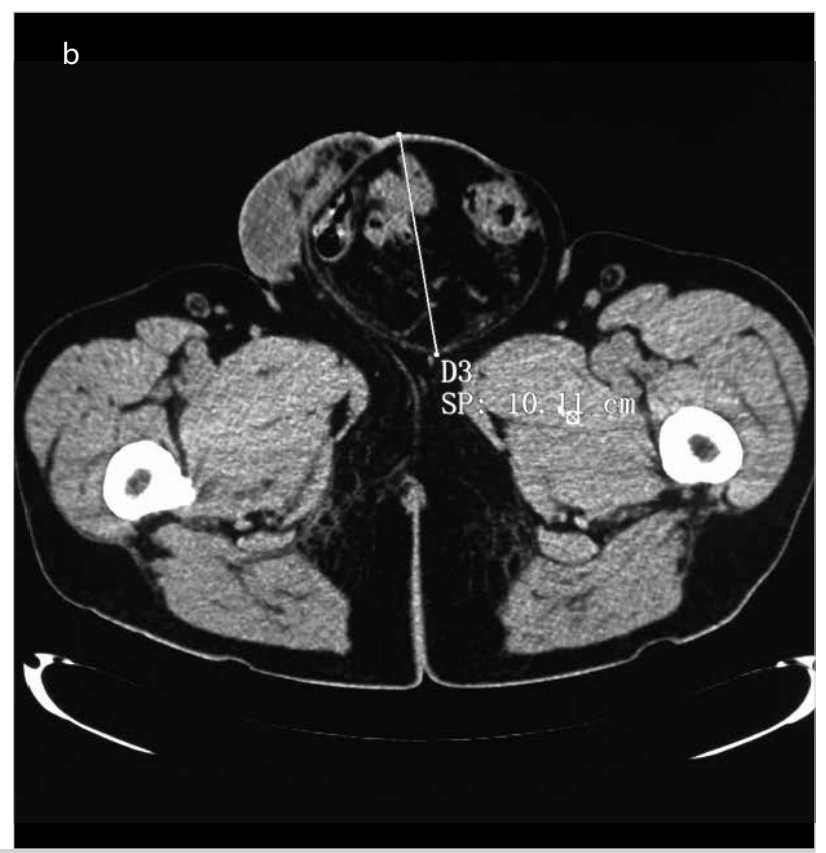

Figure 2. CT volume measurements, (a) coronal view, (b) axial view 
The CT volume and standing volume method measurements were consistent according to the Passing-Bablok regression method, and the $R 2$ values of the two methods are significantly correlated at $0.998(p=0.0001)$ (Figure 3).

Laparoscopic total extraperitoneal repair (TEP) was performed in patients whose scrotal volumes were less than $1000 \mathrm{~mL}$. In three patients with scrotal volumes between 1000 and 3000 $\mathrm{mL}$, an open posterior approach (Wantz procedure) was used. In one patient with a scrotal volume of more than $3000 \mathrm{~mL}$, surgery was omitted due to the patient's age ( 82 years) and

Table 2. Measurement confidence

95\% confidence interval

\begin{tabular}{|lccc|} 
& $\begin{array}{c}\text { Intraclass } \\
\text { correlation } \\
\text { coefficient }\end{array}$ & $\begin{array}{c}\text { Lower } \\
\text { bound }\end{array}$ & $\begin{array}{c}\text { Upper } \\
\text { bound }\end{array}$ \\
\hline CT volume/standing volume & 0.993 & 0.986 & 0.997 \\
\hline CT: computerized tomography & & & \\
\hline
\end{tabular}

Table 3. Lack of statistically significant differences between the CT volumes and the volumes $(p=0.121)$

\begin{tabular}{|lccc|} 
& CT volume & Standing volume & $\mathbf{p}$ \\
\hline Lowest value & 75 & 78 & 0.121 \\
\hline Highest value & 8880 & 9880 & \\
\hline Arithmetic mean \pm SD & $788.03 \pm 1595.23$ & $844.6 \pm 1783.52$ \\
\hline Median & 354.5 & 358.5 \\
\hline $\begin{array}{l}\text { Regression equation: } \mathrm{CT} \text { volume }=-\mathbf{3 . 2 6 3 4 + 1 . 0 2 0 6 *} \text { *tanding } \\
\text { volume }\end{array}$ & \\
\hline Intercept A & -3.26 \\
\hline 95\% Cl & & $-18.14-7.93$ \\
\hline Slope B & & 1.021 \\
\hline $95 \% \mathrm{Cl}$ & & $0.99-1.07$ \\
\hline
\end{tabular}

Cusum test for linearity no significant deviation from linearity ( $p>0.05)$

CT: computerized tomography; SD: standard deviation

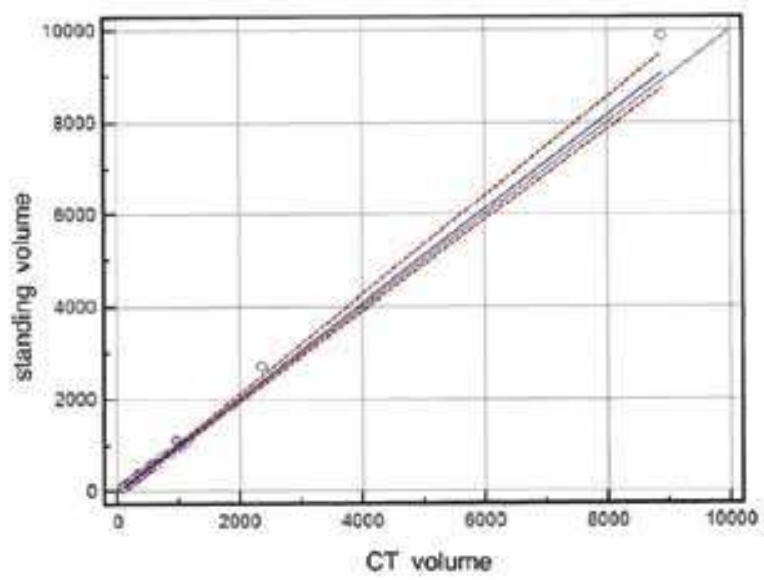

Figure 3. Passing-Bablok regression and the $\mathrm{R} 2$ values of the two methods cardiac comorbidity. This patient died four months later during follow-up. The mean follow-up period of the operated patients was 16.5 months (10 to 22 months). No recurrence or any significant complications were observed during this time. All the hernias were repaired using prosthetic meshes.

Among the 26 patients treated by TEP repair, seroma developed in 14 and hematoma in 1 patient. No recurrence was observed in the follow-up period ( 5 to 23 months, mean 13.5 months). Based on the volumetric measurements, we established a classification system of inguino-scrotal hernias and propose corresponding management. We adapted textile size codes ( $S, M, L, X L, X X L)$ to our suggested classification for simplification. This system is provided in Table 4.

\section{DISCUSSION}

The classification system of inguinal hernias should be simple, easily understandable, and easy to use in clinical settings. In this report, we aimed to introduce an objective classification system for ISHs and to propose a surgical strategy based on this system.

In the presence of scrotal hernias, because the hernia sac typically protrudes from the human body, it is possible to measure the dimensions of the hernia sac in an upright position with a caliper gage without any need for ultrasonography or CT. As we have demonstrated statistically in our study, the physical measurements provide reliable and accurate values. However, when the scrotal hernias were large, and when it was necessary to compare the scrotal (hernia sac) volume to the abdominal volume, abdominoscrotal CT scans were performed.

To calculate the volume of the hernia, a mathematical formula that is frequently used by radiologists to measure the volumes of ellipsoid structures was used $(4,5)$. In our observation, the term "giant scrotal hernia" should be used if the hernia volume is greater than $1000 \mathrm{~mL}$. In our 20 years of experience, TEP repair can be readily performed in ISHs with volumes inferior to $1000 \mathrm{~mL}$ (6). In the presence of an irreducible hernia measuring between 1000 and $2000 \mathrm{~mL}$ in volume, a transabdominal preperitoneal (TAPP) repair can be performed with a relatively larger operative space by an experienced surgeon. Ferzli et al. (7) described a hybrid procedure that combines the open and TEP techniques. Another study has suggested that TAPP repair can be successfully performed in scrotal hernias (8). In brief, depending on the surgeon's experience, a laparoscopic approach may be preferred in patients with scrotal hernias.

Table 4. The volumetry-based classification system and the proposed corresponding surgical management of inguinoscrotal hernias

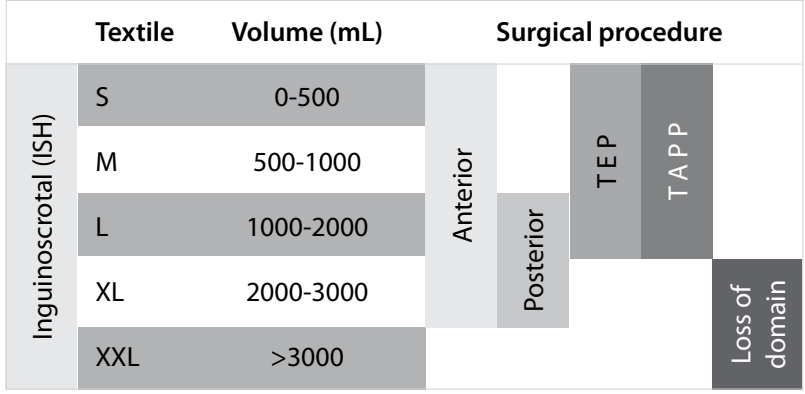


Ertem et al.

Volumetric measurement in the treatment selection of inguinoscrotal hernias

In an adult male patient, laparoscopic surgery is performed with an optimal intra-abdominal pressure of $12 \mathrm{mmHg}$, which necessitates the insufflation of $3000 \mathrm{mLCO}_{2}$ (9). Any gas volume above this value may result in disturbances in venous return and consequent cardiopulmonary problems, which together may trigger abdominal compartment syndrome. Accordingly, any scrotal hernia with a volume of $3000 \mathrm{~mL}$ or greater may induce similar problems. At these values, the relationship between the scrotal volume (SV) and abdominal cavity volume (ACV) should be taken into account $(5,10)$. If the SV/ACV ratio is superior to $25 \%$, hernia repair should be considered on the basis of loss of domain principles $(5,11)$. Furthermore, the total scrotal volume should be calculated in the presence of bilateral hernias.

\section{CONCLUSION}

Traditionally, various techniques have been used in the treatment of scrotal hernias; the use of these techniques depends entirely on the surgeon's experience. Hernia volume measurements obtained in the upright position and CT-based calculationsprovide accurate and statistically significant results, which can help determine the rational management of ISHs.

By creating a common language among surgeons, we believe that the volumetric measurement-based scrotal hernia classification system that we propose in this study will lead to further studies and discussion on the management of these hernias.

Ethics Committee Approval: Ethics committee approval was received for this study from the ethics committee of İstanbul University Cerrahpaşa School of Medicine.

Informed Consent: Written informed consent was obtained from patients who participated in this study.

Peer-review: Externally peer-reviewed.

Author Contributions: Concept - M.E., H.G.; Design - M.E., H.G.; Supervision - M.E., H.G., E.H.; Resource - M.E., H.G., V.Ö.; Materials - M.E., H.G., V.Ö., E.H.; Data Collection and/or Processing - H.G., V.Ö.; Analysis and/ or Interpretation - M.E., H.G., E.Y.; Literature Search - H.G., E.H., V.Ö., E.Y.; Writing Manuscript - M.E., H.G., V.Ö.; Critical Reviews - M.E., H.G., V.Ö.

Conflict of Interest: No conflict of interest was declared by the authors.
Financial Disclosure: The authors declared that this study has received no financial support.

\section{REFERENCES}

1. Zollinger RM Jr. Classification systems for groin hernias. Surg Clin North Am 2003; 83: 1053-1063. [CrossRef]

2. Schumpelick $V$, Arit $G$. The Aachen classification of inguinal hernia. In: Problems in general surgery. Philadelphia: Lippincott-Raven Publications; 1995; p. 57-8.

3. Miserez M, Alexandre JH, Campanelli G, Corcione F, Cuccurullo D, Pascual MH, et al. European hernia society groin hernia classification: simple and easy to remember. Hernia 2007; 11: 113-116. [CrossRef]

4. Yetter EM, Acosta KB, Olson MC, Blundell K. Estimating splenic volume: sonographic measurements correlated with helical CT determination. AJR Am J Roentgenol 2003; 181: 1615-1620. [CrossRef]

5. Tanaka EY, Yoo JH, Rodrigues AJ Jr, Utiyama EM, Birolini D, Rasslan S. A computerized tomography scan method for calculating the hernia sac and abdominal cavity volume in complex large incisional hernia with loss of domain. Hernia 2010; 14: 63-69. [CrossRef]

6. Ertem M, Gok H, Ozveri E. Standardized technique of single surgeon in TEP repair: 17 years experience. Surg Chron 2012; 17: 261-265.

7. Ferzli GS, Rim S, Edwards ED. Combined laparoscopic and open extraperitoneal approach to scrotal hernias. Hernia 2013; 17: 223228. [CrossRef]

8. Leibl BJ, Schmedt CG, Kraft K, Ulrich M, Bittner R. Scrotal hernias: a contraindication for an endoscopic procedure? Results of a single-institution experience in transabdominal preperitoneal repair. Surg Endosc 2000; 14: 289-292. [CrossRef]

9. Ishizaki $Y$, Bandai $Y$, Shimomura K, Abe H, Ohtomo Y, Idezuki Y. Safe intraabdominal pressure of carbon dioxide pneumoperitoneum during laparoscopic surgery. Surgery 1993; 114: 549-554.

10. Sabbagh C, Dumont F, Robert B, Badaoui R, Verhaeghe P, Regimbeau JM. Peritoneal volume is predictive of tension-free fascia closure of large incisional hernias with loss of domain: a prospective study. Hernia 2011; 15: 559-565. [CrossRef]

11. Yao SI, Li JY, Liu FD, Pei LJ. Significance of measurements of herniary area and volume and abdominal cavity volume in the treatment of incisional hernia: application of $C T$ 3D reconstruction in 17. Comput Aided Surg 2012; 17: 40-45. [CrossRef] 